\title{
A Dictionary of the Symphony in the Voice of Ludwig van Beethoven
}

It's dark and it comes/it's dark and it comes/it's dark and it comes and it's dark

It comes and it's dark and it comes a man on a horse and a falter in a cry and violins in the trees sequins of dresses and in the clouds it's dark it comes tasseled curtains and folded with seams

It comes it walks a bridge of skulls it wears a look it sees for miles it walks and walks it's dark it comes I can smell it I can fight it God

It's dark and it comes it's dark and it's dark it is the surface of a statue absent of limbs and the angels of coffins angels found at the mouths of graves and the men who curl soot from the root of a floor

It's dark and it will fling you over its shoulder tarnish you turn you into a schoolboy harness you the pages of it will random and fly up and its lion will fix on your sleeping face and its animal will cry at the entrance to your yard a house of cards and a stop of clocks a wing and drink of dry

It will marry you whether you accept or not it will enter your scream at the edge of the wood it will enter your color your sunset your mar it will hang as trousers do in noon's closet

You can see it if you peek into the lidlessness of flies into the filing cabinets and ashcans and books you can see it if you close your eyes you can see it if you balance or wind your features in a sheet

Close your eyes and you can see it death of mothers the mildew room 
Close your eyes and it will court you run as fast as you can and it will catch you turn the present inside out illness hours occupants remodeled all of it will smoke you out

There is no closing its wound when it is a mouth and keeps you breathing with your wide mouth inspired by all that dark the mark of a lack's hand already upon you your green grave waiting your marriage to the flesh 